\title{
Espacio y género
}

\author{
Angelique TRACHANA \\ Departamento de Ideación Gráfica Arquitectónica \\ ETSAM / Universidad Politécnica de Madrid \\ 9737trachana@coam.es
}

Recibido: $15 / 03 / 2013$

Modificado: $30 / 04 / 2013$

Aceptado: $10 / 05 / 2013$

\section{Resumen}

La asociación de los dos términos "espacio y género" plantea la hipótesis de que hay un "espacio" para el género masculino y otro para el género femenino. Pero muy lejos de la intención de este artículo es apoyar la construcción de estereotipos espaciales para el hombre y para la mujer. Lo que nos interesa es enfatizar la dicotomía y la dialéctica entre dos formas de pensar y de actuar desde un enfoque particular que es el espacio. En primer lugar, examinaremos la racionalidad occidental cientifista imbuida por la idea de dominio que crea la lógica espacial. Su opuesta es la lógica de la acción, una lógica contextual e interpretativa, no formal, ni visual, articulada por la temporalidad vivida y cualitativa. Asociaremos estas lógicas con el habitar y la ciudad y, por último, haremos algunas consideraciones sobre la planificación urbanística desde el punto de vista y el uso de la ciudad por las mujeres.

Palabras clave: espacio, razón, poder, acción, comunicación, mujer, ciudad.

Title: Space and Gender

\section{Abstract}

The association of the terms "space and gender" hypothesizes that there is a "space" for males and another one for females. But the intention of this article is far from supporting the construction of spatial stereotypes for men and women. What interests us is to emphasize the dichotomy and dialectic between two ways of thinking and acting from a particular approach that is the concept of the space. First, we will examine the Western scientific rationality imbued with the idea of domain that creates the logic of space. Its opposite is the logic of action that is contextual and interpretive, nonformal, non-visual and articulated by the lived and qualitative temporality. We will associate these logics with the dwelling and also with the city and, to finish up, we will make some considerations on urban planning from the point of view of the use of the city by women.

Keywords: space, reason, domain, action, communication, woman, city.

\section{Índice}

1. Espacio y poder

2. Espacio-acción

3. Habitar poiético

4. La mujer y la ciudad 


\section{Espacio y poder}

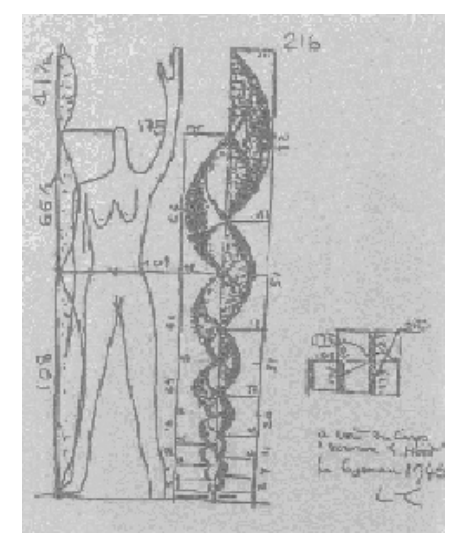

La asociación de los dos términos "espacio y género" constituye un par dialéctico que plantea la hipótesis de que el "espacio" crea una división localizadora de los dos sexos humanos, de tal manera que hay un espacio para lo "masculino" y otro para lo "femenino". La experiencia de que no todos los espacios son propios de ambos géneros está muy arraigada en nuestra cultura y dirige nuestra conducta sin que siquiera lo advirtamos. Es propio de nuestra cultura occidental que el "espacio" se convierta en una categoría mental clasificadora y que sea también la medida para la comprensión del tiempo (Ramírez 1996).

Siendo el "espacio" una categoría totalizadora de la extensión a la que los cuerpos se hallan sometidos, se establecen en él históricamente ámbitos separados para los dos géneros: el ámbito del ágora para el hombre, y el ámbito privado, la oikia para la mujer. Los espacios para cultivar el cuerpo -la palestra y el gimnasio- estaban destinados al hombre, mientras que los espacios para cultivar el alma - los espacios para los misterios y los rituales-, estaban reservados a la mujer en la antigua Grecia (Sennett 1997).

En la civilización occidental que emana de la antigua Grecia los espacios "masculinos" - desde el gimnasio y la palestra a la academia, el parlamento (boulé) y la asamblea popular (ekklesia de demos)están impregnados de lo más característico del espíritu clásico griego: el espíritu de la competición y de la selección (de los mejores). La paideia griega preparaba una sociedad física e intelectualmente para que sus miembros (hombres) pudieran destacar y asumir posiciones de liderazgo. Así la civilización occidental se ha basado en la diferencia, y no sólo entre los sexos humanos.

"Espacio y poder" se presentan ligados en nuestra cultura. La categoría del espacio, viene a constituir un paradigma mental que marca la pauta del pensamiento y de la acción en nuestra sociedad y nuestra cultura. El espacio socio-cultural es un espacio mental. 
Cuando encima del pórtico de la Academia de Platón aparecía aquel letrero que prohibía la entrada a quien no supiera geometría, se declaraba abiertamente que el camino de la filosofía y de la ciencia, es decir, el camino del progreso y del poder estaba reservado a un pensamiento estructurado por el modelo espacial que sería administrado por un sector dominante representativo de los valores viriles.

La identificación entre espacio y civilización y entre éstos y la masculinidad es una clave fundamental explicativa del elemento griego identificador de nuestra cultura. El otro elemento, lo "femenino", como elemento diferencial, actúa como justificador de la identidad dominante. El hombre necesita lo femenino para confirmar su identidad. Nos identificamos por relación a lo diferente. Sin embargo, la identidad femenina arranca de la consideración de lo otro sin destruir sus matices diferenciales. La mujer, en nuestra cultura, se ha habituado a hallar su propia identidad partiendo de la conciencia de que no es hombre y de la consideración respetuosa de que los otros existen; se identifica afirmando a los demás.

Pero la oposición dominante en la mentalidad occidental es la que no distingue otra cualidad en los otros que la de "otros". No advierte la pluralidad y nutre una identidad narcisista en que lo otro es solamente el espejo para verse y reconocerse. Esa forma dicotómica y asimétrica de oposición es "voluntad de poder" originadora tanto del etnocentrismo como del falocentrismo, pero también del pensamiento abstracto, silenciador de toda pluralidad mediante la mecánica reduccionista de los conceptos universales.

La racionalidad occidental cientifista, imbuida por la idea de dominio, crea así la lógica espacial cuya ciencia es la geometría. Como toda lógica formal necesita crear conceptos abstractos universales. La imposición de lo espacial como patrón de lo racional es el dominio de lo visual estático sobre lo fluyente cenestésico. El pensamiento abstracto trajo la concepción abstracta de la ciudad y la planificación urbana. Entonces la "ciudad" que designa una estructura espacial ha suplantado la civitas romana designadora de la actividad ciudadana. El "ayuntamiento" pasa a ser una casa y una institución, en lugar de ser la comunidad de los ciudadanos, con lo cual la actividad de estos se enmarca en un espacio construido y el poder del pueblo ("democracia") viene a confundirse con el parlamentarismo, que son sus reglas (formales) de juego.

En el arte, el formalismo, la pura visualidad y la teoría del espacio vienen a ser antitéticos a la comunicación intersubjetiva en la vida corriente. La visualidad hegemónica presupone códigos de entendimiento y resulta, por eso, excluyente, impositiva y autoritaria. El saber del cuerpo, inconsciente e intuitivo, es, sin embargo, productivo de saber original, genérico, madre de todas las artes (Nancy 2003). Esta forma de "hacer" implica un cierto arcaísmo en el 
plano creativo o destrucción de los códigos establecidos y de las convenciones del "lenguaje"; un estado anterior al que los sentimientos espontáneos fuesen socavados por la razón.

El dominio mental del espacio origina todo un sistema jerárquico de categorías. Pensar racionalmente es, en su origen, identificar y distinguir. El sistema de espacios sociales no sólo discrimina a la mujer sino que también relega a niveles inferiores al niño, al anciano, al enfermo, al homosexual, etc. El hecho de que el género sea más visible en esa jerarquía es porque se convierte en la dicotomía que afirma lo uno mediante la negación de lo otro. La guerra no supone otra cosa sino la implementación total del espacio, en un intento de desterrar de él totalmente lo diferente. El trato dado en nuestros días a los exiliados o los emigrantes es también prueba de una idiosincrasia reacia a compartir su espacio con el extraño.

El urbanismo barroco, el jardín de trazado geométrico, la plaza porticada, las grandes avenidas concebidas para los desfiles militares, los espacios ideados para la predicación, los espectáculos y los deportes, son espacios reglamentados, espacios que dictan unas normas y unas direcciones; que imponen una compostura y un comportamiento. Los lugares donde la palabra domina para persuadir y seducir siguiendo esa lógica, podríamos afirmar, que encierran en su concepción una voluntad de imposición.

\section{Espacio-acción}

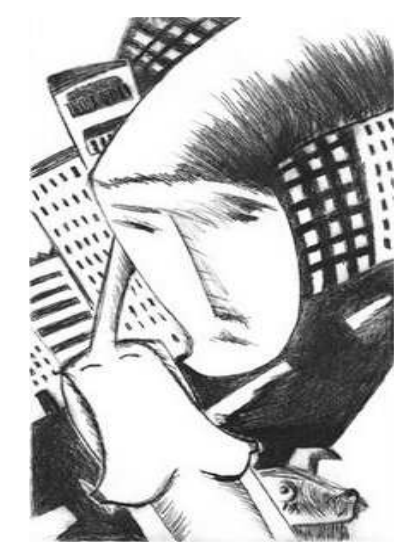

Sin embargo, la calle, el mercadillo, el huerto,... los espacios donde actuamos e intercambiamos libremente, desarrollamos relaciones intersubjetivas y comunicativas son, por antítesis, podríamos decir, espacios "femeninos". Habría que incluir aquellos poco conformados (con la geometría), a veces improvisados y efímeros; y aquellos que surgen espontáneamente desde abajo como reivindicación de espacio vital en las ciudades, hoy densamente edificadas y carentes de espacios libres. Podríamos añadir también los espacios donde se recrea la naturaleza en las áreas urbanas, los espacios residuales 
creativamente reutilizados, los cascos históricos que todavía se conservan por su población, los centros asistenciales y todos aquellos donde se actúa con una lógica respetuosa con el otro, con lo encontrado-preexistente, con la pluralidad y la participación. Nuevos paradigmas de espacios sociales informales emergen hoy día con fuerza fuera de las regulaciones urbanísticas, también como consecuencia de la escasez de recursos económicos a causa de la crisis económica y financiera.

Si la mentalidad bélica y destructiva, el autoritarismo y la imposición, históricamente han sido identificados con la "mentalidad masculina", por oposición "la mentalidad femenina" se identifica con la adaptación y la conservación. La transformación y la adaptación de lo dado son propias de una creatividad femenina contingente. Cuando lo dado o el resultado domina sobre el "hacer", estamos ante una metafísica ontológica del "hecho" masculino. Frente a la lógica del espacio, de la diferencia, de la imposición y el "hecho", se opone la "lógica de la acción", del "discurrir", de la "deriva" que es una lógica no formal, una lógica contextual e interpretativa. Esa es una "lógica del lugar", no del espacio.

El "lugar está en uno", sostiene Hannah Arendt (2002), sólo es un lugar del "espíritu", es un pensar y "para existir no se necesita de ningún lugar". El sujeto no está sino que trabaja; es el ser concebido como no-posición que, por eso, sólo puede ser dis-posición: apertura, expectativa ante lo que en cada momento está a punto de ocurrir. En la lógica totalitaria del espacio cuenta solamente lo dado y la presencia. En cambio, la lógica de la acción está articulada por la temporalidad vivida y cualitativa, no por la temporalidad espacial o cronológica. Los espacios de acción y expresión, comunicación intersubjetiva, donde tiene lugar la celebración de las efemérides, son "lugares", según Marc Augé (1994), por oposición a los "no lugares", que son lugares carentes de comunicación y de memoria.

La conducta femenina se ha descrito como una conducta comunicativa y performativa. Como un importante sector dentro del arte y tal como se había suscitado por los situacionistas (Debord 1957), actúa considerando que lo esencial es la acción espontánea y directa sobre una realidad, las situaciones, la interacción con los otros, no la autoría. La afirmación de que la conducta femenina es performativa indica la aberración femenina hacia las esencias (los valores universales y atemporales) que es, por el contrario, voluntad de transformación de lo dado (Schechner 2003). Esta idiosincrasia es sensible a los efectos precisos del medio que actúan sobre su comportamiento afectivo (psicogeografía). El trabajo corriente de la mujer se diluye en la familia, en el grupo. Su premisa fundamental es el sujeto descentrado, el cuerpo extenso, "ser" frente a los mitos centrales, "la acción que resiste a los actos" (Agamben 1998). 
La conducta performativa es más artesana que científica, e imbuida en el tiempo de la acción-reacción, en la vida cotidiana, dentro de un contexto concreto donde la implicación y el compromiso adquieren una importante dimensión en este tipo de acción. Los modos de interpretar y de relacionarse en el espacio constituyen, consecuentemente, un posicionamiento subjetivo frente a las cosas $y$, por tanto, crítico (Read 1982). El mejor y más efectivo modo de actuar es a través de un conocimiento instintivo y una conciencia del entorno en la que pueden correlacionarse sensaciones y reflexiones, imágenes y conceptos.

La experiencia de la realidad como una experiencia del cuerpo y de la acción, que involucra los sentidos, los deseos y las limitaciones físicas constituye un saber biológico y antropológico, un estado cognitivo mucho más complejo que el racionalismo. Este entendimiento actualmente forma parte de importantes cambios metodológicos que se están produciendo en las disciplinas que estudian la ciudad. Frente a las clasificaciones nítidas, las categorías abstractas y las representaciones de las ciudades a través de sus espacios míticos, se trata de la legibilidad de la consistencia magmática de lo "urbano" (Delgado 2007). Los estudios más innovadores de la ciudad hoy se centran en desvelar esas partes desapercibidas y desatendidas del transcurrir de la "vida cotidiana" (De Certeau 1999), de la actividad ciudadana.

Richard Sennett (1997) distinguía dos tipos de espacio público: espacios tipo "ágora" y espacios tipo "foro". En su esencia, estos últimos son espacios de representación y nos vienen dados. En ellos acontecen las efemérides y los rituales extraordinarios. Los otros son, sin embargo, dinamizadores del devenir de la vida ciudadana cotidiana y de la expresión libre. En los "foros" transitan las ideas abstractas, los discursos y las utopías; son espacios ideológicos asociados a clases de poder y personajes como sus propios nombres indican. Pero los verdaderos espacios públicos de la ciudad no se pueden reducir a aquellos cuyo significado emana de su diseño arquitectónico y su programa de uso definido en el proyecto. La percepción de un espacio depende de una interpretación, del uso espontáneo que se le dé y muchas veces de una refundación (Trachana 2012).

Pero los espacios cuya esencia no son la representatividad ni la productividad ni la rentabilidad económica sino el simple disfrute, presentan poco o ningún interés para los poderes económicos y políticos. El urbanismo institucional se fundamenta sistemáticamente en modelos que se basan en comportamientos miméticos, ya que la espacialización de la experiencia social supone la creación de identidad (Stavridis 2003: 59). Los poderes fácticos limitan así toda iniciativa espontánea y oprimen todo lo imprevisto a través de una tarea sistemática de convertir los espacios de la ciudad en espacios 
normativos determinando las formas, los usos y las explotaciones (privadas) del espacio público, convirtiendo a los ciudadanos en clases de consumidores y espectadores.

Asciende, sin embargo, hoy rápidamente una percepción de la ciudad como espacio donde se articulan las identidades minoritarias, disidentes y subalternas, la resistencia a los poderes hegemónicos y la trasgresión de las regulaciones. Esta concepción, que implica la idea de participación y de compromiso en la configuración de la ciudad, se opone a la arquitectura como espectáculo y al proyecto del espacio urbano como subproducto de la ideología mistificadora de los gustos de clase, del poder económico, y del consumo mimético; se opone a las visiones de la realidad urbana desde puntos de vista técnicos específicos y entiende la ciudad como un campo interdisciplinar.

En efecto, afloran hoy día diversas tendencias de producción de espacio bajo una visión más globalizadora de la ciudad y una conciencia más solidaria con los ciudadanos valorando su participación en los procesos. La creación de esos nuevos espacios enarbola "políticas de coalición", promueve lo nuevo a partir de las preexistencias y hace emerger una "conciencia contestataria" como clave para contrarrestar el nihilismo tecnocrático y los intereses económicos en un mundo globalizado. El uso de las nuevas herramientas tecnológicas de la información y la comunicación facilita la interacción y nos permite acceder a una nueva reflexión sobre la ciudad a través de ellas.

\section{Habitar poiético}

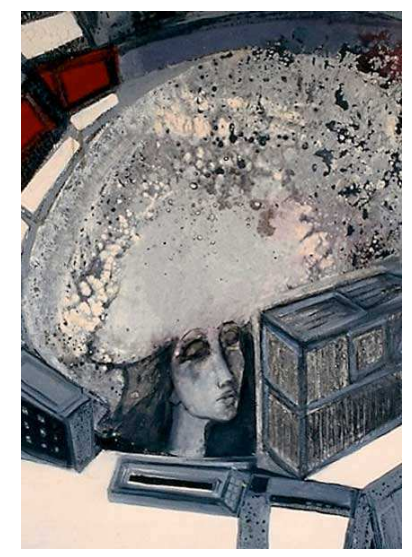

Como se puede advertir, muy lejos de la construcción de estereotipos espaciales para el hombre y para la mujer, nos enfrentamos a dos formas de pensar y de actuar en el espacio. Si la arquitectura, como se ha dicho, es el arte del espacio, el espacio se puede pensar de una forma transversal e interdisciplinar. Reivindicar para la ciudad los espacios vitales implica una visión diferente de la "arquitectura de 
autor" y del urbanismo institucional. Implica formas creativas de intervenir en el entorno y la reutilización creativa de espacios que surgen del impulso de alterar un estado interior o de comunicar algo a los demás, capaz de alterar su estado interior. Mediante la actividad creativa el individuo puede conocer el mundo y conocerse a sí mismo y su relación con el mundo. En la base de la acción generativa de un espacio para el disfrute de los demás subyace siempre el deseo y el placer propio de "hacer". No se trata de una forma egoísta de expresión, sino de diluir lo personal en lo colectivo, de abrir momentos de libertad y definir zonas que escapen del control "totalitario" del diseño de "autor" que sufren tan a menudo los espacios públicos de la ciudad. Una acción urbana, en la que las personas se impliquen y participen en la creación del espacio, que se lo puedan apropiar y darle una continuidad temporal, termina convirtiéndose en un evento donde los participantes son al mismo tiempo actores y espectadores. Sin personas ninguna intervención tendría sentido y vida, es decir, sin tener en cuenta la gente y ser para la gente. Así, este tipo de espacios se convierten en evento para una sociedad de espectadores (Trachana 2012).

Como cambio radical también de las disciplinas arquitectónica y urbanística, su fin último no será quizá la producción de las mejores obras, sino de los espacios que se hacen con una sabiduría generadora de compensaciones y equilibrios, propiciadora de felicidad, que los hacen más humanos e integradores. Actualmente numerosos colectivos de base ciudadana y profesionales de distintas disciplinas en todo el mundo promueven procesos sencillos y diáfanos movidos por una sensibilidad por el otro y por el entorno. Son prácticas en campos fértiles de creatividad, en el dominio de la validación empírica donde el arte tiene la capacidad de vivificar lo concreto. El actuar, el construir, el modelar el entorno con los demás y entre los demás se sitúan en el ámbito del proyectar autopoiéticoinnovador y el producir intuitivo antes que el pensar o racionalizar desde una teoría (Arendt 1995).

Los espacios vitales, que son la praxis misma, no se focalizan en objetos, en la obra, sino en el evento donde los sujetos dejen de ser sujetos pasivos y, con su actuación, alcanzan una liberación a través de la expresión emotiva y la representación colectiva. La participación, la interacción, la improvisación, la imprevisibilidad, la espontaneidad, el carácter colectivo, cotidiano y efímero, son todos ellos los ingredientes de la praxis configuradora de espacios convivenciales. La habitabilidad de las ciudades depende de la actividad y la vitalidad, y no tanto de elementos arquitectónicos fijos y obras bien diseñadas y perfectamente realizadas. El entendimiento del espacio de la ciudad como un espacio constituido por la acción de los seres vivos móviles y movilizados por la acción (Delgado 2007; Lefebvre 1978), frente al estable, consolidado y formado por los 
edificios y los monumentos, el espacio de la ciudad, frente a su arquitectura estabilizada y estabilizadora de valores -ideológica-, se presenta como opción de proyectar espacios dinámicos y fluctuantes al ritmo de la vida humana.

La esencia del habitar del ser humano es poética, narraba Heidegger (1994) a través del verso de Hölderlin: "poéticamente habita el hombre". La poesía es imaginación, es un pensar no con la geometría sino con el sentimiento, es un trascender de la semiología a lo arbitrario-subjetivo que es un habitar originario. Pero la fantasía, el "eterno femenino", como lo expresa Goethe en Fausto, que "nos tira hacia adelante", sufre ataques por todos los lados en el mundo moderno. Cuanto más avanzada es la civilización de una sociedad, más tecnocrática, más diferenciadora y segregadora resulta. EI desarrollo tecno-científico tuvo como consecuencia la conversión urbana del medio natural con la separación del hombre de la tierra, la industrialización, el proletariado obrero y el urbanismo del zoning como taxonomía social.

Reivindicar hoy la ciudad como una "ciudad viva" es reivindicar una ciudad vivida con los sentidos y una ciudad sensorial alerta que reacciona a todo tipo de solicitaciones. Esa sería una ciudad compleja y plural, no excluyente, con espacios vivos y no monumentos inertes. Sería una ciudad plurifuncional, donde trabajan diferentes colectivos interrelacionando disciplinas de distintos ámbitos, respondiendo directamente a las necesidades de los ciudadanos con un fuerte componente práctico. Esa sería una "ciudad creativa" si las respuestas de los ciudadanos fueran imaginativas (Florida 2009). Además, la ciudad hoy como realidad ampliada y enriquecida con información y conocimiento a través de los nuevos medios tecnológicos, tiene una consistencia híbrida entre la realidad construida y la virtualidad de los relatos, los recuerdos, las imágenes y todo tipo de mediaciones que intensifican su percepción y motivan la pro-actividad y la creatividad de los ciudadanos (Trachana 2013).

El entendimiento de la ciudad reclama así la convergencia de ciencia y humanidades, de tecnología y arte, de reflexión y comunicación; razón e imaginación. Este par antitético que fue expresado en el ambiente de la Viena finisicular por Carl Kraus como "el encuentro del hombre con la mujer", que fue el "origen" en que la razón quedó fecundada por la imaginación, nosotros diríamos, que producto de este encuentro de la "mentalidad femenina" y la "mentalidad masculina", y no exactamente de los dos géneros, es la creatividad y la integridad moral. Siguiendo a Kraus, la esencia emocional "femenina" "no es desenfrenada o nihilista" sino más bien "tierna fantasía", que viene a ser el origen inconsciente de todo lo que tiene algún valor en la experiencia humana. En ella descansa la fuente de toda inspiración. La razón en cuanto tal es meramente una técnica, un medio por el cual los seres humanos obtienen lo que 
desean $y$, en cuanto tal, no es ni buena ni mala, sino efectiva o inefectiva. A la razón se le tienen que suministrar desde fuera unos objetivos de tipo "estético o moral". Por eso, cuando el feminismo se convirtió en movimiento de lucha por el poder, como lamentaba Kraus, tal vez, se intentaban erradicar los propios manantiales de la civilización (Janik y Toulmin 1987).

En la unión entre lo "femenino" y lo "masculino" se consuma la unión de lo personal con lo colectivo. El impulso idealista que proyecta una visión subjetiva sobre el mundo entra en tensión con el programa mecanicista que incide con una orientación cosmológica. Pero en los nuevos relatos de la ciudad que se visten de carácter "ecohumanista" seguimos encontrando todavía encubiertas intenciones que operan mítica y simbólicamente en el medio apoyándose en valores egocéntricos y más bien dogmáticos. Pues esas intervenciones siguen siendo deudoras de la cultura ilustrada que deriva hacia la actual cultura de masas. Rezuman así de actualidad propuestas cuyo dominio de actuación es el arte que interviene sólo como sustitución gratificante de la falta de armonía en el entorno, y como mediador en la angustia y la desazón emocional causadas por la fealdad de los lugares (De Gracia Soria 2009).

El urbanismo moderno anunciaba la libertad individual y el disfrute del "tiempo libre" con el concepto de "espacio libre" que acercaría la ciudad a la naturaleza, a la vida saludable y el deporte. Este urbanismo social e higienista arrancaba efectivamente de una Ilustración deudora del paradigma griego de educación y su predilección por la vida saludable al aire libre. Pero como se demostró, no fue más que una "fantasía" incrustada en la ciudad moderna que pronto se desvaneció, al reconocerse que el ideal del "espacio libre" y su "neutralidad indiscriminada o uniformidad igualitaria resultaba apenas alcanzable, ni siquiera deseable" (Rowe y Koetter 1981).

Con la estandarización de las condiciones de habitar y de la socialización, el urbanismo moderno no hizo otra cosa que aportar sectorialización a la sociedad según el poder adquisitivo de las clases sociales. Y eso, según la filosofía funcionalista del zoning. Si hemos detectado hasta aquí la dicotomía entre espacios vitales o espacios para la acción y espacios estáticos para la representación, hablaríamos ahora de géneros de espacio, no de un espacio de género. 


\section{La mujer y la ciudad}

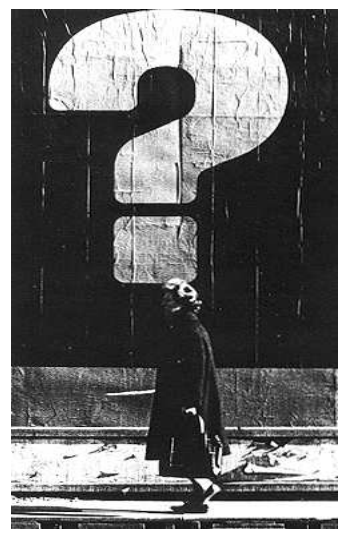

La reivindicación del punto de vista femenino en el diseño del espacio urbano es muy reciente. Esta reivindicación no sólo se dirige a la mejora de las condiciones vitales de las mujeres en la ciudad desarrollando sus múltiples roles entre el mundo del trabajo, el hogar y la vida social. Lo que reivindicamos hoy, tanto mujeres como hombres, es el espacio plural de igualdad de oportunidades y de solidaridad para desarrollar nuestra actividad. Pero estos son valores, y no atributos del espacio. Son valores que pueden ser infundidos en acciones para configurar espacios sin género, espacios abiertos, polivalentes, sin divisiones por clase, género, etnia o cultura. Si los hombres han tenido siempre sus espacios específicos para desarrollar sus actividades sociales y políticas, el espacio ocupado por la mujer, en los distintos sistemas sociales, ha sido un espacio compartido.

Tomás Moro en su Utopía no distinguía a la mujer del hombre más que por sus aptitudes para ciertos oficios. Pero hasta el Renacimiento, la mujer se adhería a las virtudes del hombre y de la familia y, sobre todo, a la tierra. La tierra naturaleza constituía una concepción femenina o feminización de la naturaleza como la "madre tierra". Es a partir del Renacimiento, con la revolución científica e industrial, cuando se inició el eclipse de los saberes femeninos por el cientifismo masculino que ha sometido la naturaleza a la explotación hasta el agotamiento de sus recursos.

La antropología enfoca también la dicotomía femeninomasculino desde el espacio, distinguiendo entre el espacio doméstico y el espacio público, en relación con el hombre y la mujer respectivamente. Con la incorporación de las mujeres al trabajo por cuenta ajena -las mujeres pertenecientes, más bien, a las clases humildes-, los espacios femeninos fueron asociados al trabajo de salarios bajos para la atención hospitalaria, el servicio de oficinas, la limpieza, etc. El acceso de las mujeres a la alfabetización y al conocimiento fue más tardío que la de los hombres, dependiendo de la clase social, y asimismo a la vida cultural, por no hablar de la vida 
política y el sufragio universal, que no fueron logrados, según los países, hasta muy avanzado el siglo XX. En las clases sociales y culturales más altas, la emancipación de la mujer y la apropiación de espacios por ella se produjo de modo distinto con su incorporación a trabajos más cualificados, al mundo del ocio y los deportes al aire libre -como el croquet, por ejemplo, en el siglo XIX, o el tenis en las primeras décadas del siglo $X X-Y$, como se ha señalado tantas veces, los espacios por antonomasia de la emancipación de la mujer fueron los grandes almacenes.

Muchos fueron, en los siglos XIX, XX y lo que va del siglo XXI, los caminos del cambio hacia una sociedad más plural. Pero las inercias y la adherencia a los valores masculinos siguen siendo predominantes, aunque no seamos conscientes de ello. En la disciplina del urbanismo, entre los modelos que se barajan, todavía predomina el modelo familiar tradicional basado en la división del trabajo entre los géneros. Este fue el ideal del urbanismo moderno, donde se daban además la división de la vida laboral y la vida familiar, la separación de las zonas de trabajo, de las zonas residenciales y del ocio, y la movilidad motorizada entre las diferentes zonas.

Hay numerosos estudios que constatan las diferentes formas de uso del espacio como, por ejemplo, la movilidad de las mujeres respecto a la de los hombres durante las décadas de su ya plena incorporación en el trabajo. Como se ha comprobado, las trayectorias de las mujeres eran más cortas debido a un trabajo localizado mucho más cerca del domicilio familiar y, por tanto, condicionado por esa necesidad (Tobío 1996). Esta diferencia no dejará de persistir hasta hoy que, con el advenimiento de las TICs, muchas más mujeres que hombres han optado por compaginar trabajo y hogar.

En efecto, como se manifiesta en la Carta Europea de la Mujer en la Ciudad $^{1}$, las mujeres tienen necesidades propias en relación al espacio urbano que se derivan, fundamentalmente, de su dedicación a las tareas de mantenimiento del hogar, el cuidado de los niños, ancianos, incapacitados o de la doble jornada laboral y doméstica. Esas diferencias socialmente construidas como roles de género, no diferencias de sexo, han ido modificándose rápidamente en las

1 La Carta Europea de la Mujer en la Ciudad (1996) fue un proyecto de investigación subvencionado por la Comisión de la Unión Europea (Unidad de Igualdad de Oportunidades). Contiene una evaluación de la situación de las mujeres en las ciudades basándose en un análisis de cinco temas prioritarios (planeamiento urbano y desarrollo sostenible, seguridad, movilidad, hábitat y equipamientos locales, estrategias), una base de datos informatizada de recursos humanos, más referencias biográficas y un catálogo de las 66 "mejores prácticas" (se añaden continuamente casos nuevos). El propósito de la Carta era establecer una red informática internacional capaz de sacar conclusiones de estos casos desde el punto de vista del género. 
últimas décadas por la voluntad de mujeres y hombres. Contemplar ahora esta cuestión desde el punto de vista del cambio de la posición social de las mujeres ( $y$ de los hombres) introduce una mayor complejidad, ya que no se trata de reivindicar una adaptación de la ciudad a roles estáticos, sino una planificación urbana flexible y coherente con los nuevos modelos sociales y familiares.

Pero las ciudades y los barrios se siguen planificando mayoritariamente como si la familia tradicional siguiera siendo el modelo dominante, quizá por la fuerte inercia del espacio construido. Entre otros, se pueden señalar tres aspectos contradictorios entre la ciudad funcionalmente segregada y el tipo familiar basado en la doble ocupación de la pareja o de la familia monoparental o unipersonal. En primer lugar, la secuencia diaria de vaciado / llenado de los espacios cada vez más numerosos: centros terciarios de negocios, polígonos industriales, ciudades dormitorio con una creciente segregación y aislamiento de los barrios residenciales, rígidos mecanismos de ocupación de viviendas, reducida proporción de alquiler. EI protagonismo en la gestión del modelo resultante se desplaza a los medios de transporte, con un aumento insostenible de la demanda de transporte, aumento de los desplazamientos al trabajo, sobre todo, en automóvil privado, a medida que disminuyen los desplazamientos a pie con destino a compras, colegios, actividades culturales, etc. Pero el dato más significativo, sin entrar en los índices numéricos, es que la movilidad de las mujeres que trabajan es mayor que la de los hombres que trabajan en puestos parecidos (Tobío 1996). Eso es fácilmente comprensible por el doble rol que sigue manteniendo la mujer entre trabajo y hogar y, una vez más, señala las grandes contradicciones del suburbio monofuncional con los nuevos modelos económicos y familiares.

Se constata, por tanto, que la percepción y el uso de la ciudad es para las mujeres diferente; y que esa especificidad está todavía escasamente considerada en la planificación urbanística. La Carta Europea de la Mujer en la Ciudad planteaba la reivindicación del punto de vista de las mujeres en el diseño del espacio urbano y enfocaba una nueva investigación sobre la ciudad. La propuesta fue planteada en el marco del Programa para la Igualdad de Oportunidades de las mujeres en la Unión Europea, pero hoy esa referencia, como hemos tratado de demostrar aquí, constituye el punto de vista de diferentes áreas del conocimiento, del arte y de la acción propiamente en la ciudad y, sobre todo, tiene una repercusión importante en la educación donde se incuban las nuevas actitudes. 


\section{Bibliografía}

AGAMBEN, Giorgio (1998): El hombre sin contenido. Primera edición: 1970. Barcelona: Áltera.

ARENDT, Hannah (1995): De la historia a la acción. Barcelona: Paidós.

AUGÉ, Marc (1994): Los no lugares, espacios del anonimato: una antropología de la sobremodernidad. Primera edición: 1992. Barcelona: Gedisa.

DE CERTEAU, Michel (1999): La invención de lo cotidiano. Primera edición: 1990. México DF: Universidad Iberoamericana.

DE GRACIA SORIA, Francisco (2009): Entre el paisaje y la arquitectura. San Sebastián: Nerea.

DEBORD, Guy (1999): La sociedad del espectáculo. Primera edición: 1967. Valencia: Pre-Textos.

- (1957): "Manifiesto Situacionista. Informe sobre la construcción de situaciones y sobre las condiciones de la organización y la acción de la tendencia situacionista internacional" [en línea]. Revista Bifurcaciones, núm. $5 . \quad$ En: http://www.bifurcaciones.cl/005/reserva.htm [Consulta: enero de 2011].

DELGADO, Manuel (2007): Sociedades movedizas. Barcelona: Anagrama.

FLORIDA, Richard (2009): Las ciudades creativas. Por qué donde vives puede ser la decisión más importante de tu vida. Primera edición: 2008. Barcelona: Paidós.

HEIDEGGER, Martin (1994): "Poéticamente habita el hombre", en Conferencias y artículos. Barcelona: Ediciones del Serbal.

JANIK, Allan; y TOULMIN, Stephen (1987): La Viena de Wittgenstein. Madrid: Taurus.

LEFEBVRE, Henri (1978): El Derecho a la ciudad. Traducción de J. González-Pueyo; prólogo de Mario Gaviria. Primera edición: 1969. Barcelona: Península.

MORO, Tomás (1999): Utopía. Madrid: Espasa Calpe.

NANCY, Jean Luc (2003): Corpus. Primera edición: 1962. Madrid: Arena Libros.

RAMÍREZ, José Luis (1996): "El espacio del género y el género del espacio". Astrágalo. Cultura de la arquitectura y la ciudad, núm. 5, pp. 9-28.

READ, Herbert (1982): Educación por el arte. Barcelona: Paidós.

ROWE, Colin; y KOETTER, Fred (1981): Ciudad Collage. Primera edición: 1979. Barcelona: Gustavo Gili.

SCHECHNER, Richard (2003): Performance Theory. Primera edición: 1977. New York: Routledge.

SENNETT, Richard (1997): Carne y piedra. El cuerpo y la ciudad en la civilización occidental. Primera edición: 1994. Madrid: Alianza. 
STAVRIDIS, Stavros (2003): De la ciudad pantalla a la ciudad escena [título traducido]. Athina: Ellinika Gramata.

TOBÍO, Constanza (1996): "Zonificación y diferencias de género". Astrágalo. Cultura de la arquitectura y la ciudad, núm. 5, pp. 61-75. Madrid: Instituto Español de Arquitectura de la Universidad de Alcalá / Celeste Ediciones.

TRACHANA, Angelique (2012): "Urbe Ludens. Espacios para el juego en la ciudad". CYTET, vol. XLIV, núm. 173, pp. 423-444. Madrid: Ministerio de Fomento.

- (2013): "La ciudad sensible. Paradigmas emergentes de espacios informales y usos alternativos del espacio urbano". Urban, núm. 5, pp. 97-111. Madrid: Departamento de Urbanística y Ordenación del Territorio. 